\title{
OPTIMAL LAYOUT OF MULTI-FLOOR PROCESS PLANTS USING MILP
}

\author{
Jude O. Ejeh ${ }^{\mathrm{a}}$, Songsong Liu ${ }^{\mathrm{b}}$, Lazaros G. Papageorgiou ${ }^{\mathrm{a}, *}$ \\ ${ }^{a}$ Centre for Process Systems Engineering, Department of Chemical Engineering, University \\ College London, Torrington place, London WC1E 7JE, UK \\ ${ }^{b}$ School of Management, Swansea University, Bay Campus, Fabian Way, Swansea SA1 \\ $8 E N, U K$
}

\begin{abstract}
In this work, a new mixed integer linear programming (MILP) model is proposed for the multi-floor process plant layout problem with additional considerations. Multi-floor process plant layout determines the spatial arrangement of process plant units considering their connectivity amongst other factors and affects the cost of constructing the plant, the ease of plant operation and expansion, general safety levels within the plant and its neighbouring environment, as well as operational costs. Over the past years, mathematical programming models have been developed to describe the layout problem considering connectivity costs, pumping costs, installation of safety devices, and piping, in single and multiple floors. Features such the representation of irregularly shaped items, tall equipment spanning multiple floors and others have been successfully modelled. This work builds on such past considerations with additional features that allow multi-floor equipment items extend above the maximum potential number of floors, and the selection of an available number of floors less than the maximum number required by any equipment item. Integer cuts are also developed for the proposed model to enhance its efficiency. The performance and limitations of the proposed model are demonstrated with industry-relevant case studies of up to 25 units, and results show a potential cost savings when compared to existing models with additional computational benefits of the integer cuts in all of the cases explored.
\end{abstract}

Keywords: multi-floor process plant layout, mixed integer linear programming (MILP), optimisation

\section{Introduction}

There has been an upward trend in the cost of land as well as a growing concern of space availability not just for the establishment of new chemical pro-

\footnotetext{
*Corresponding author. Tel: +44 (0)20 76792563

Email address: 1.papageorgiou@ucl.ac.uk (Lazaros G. Papageorgiou)
} 
cess plants but for the expansion of existing ones (Hosseini-Nasab et al., 2018). This, combined with the ever increasing need to operate chemical process plants at reduced costs and increased efficiency without compromising general safety levels, has given more focus to the layout design of chemical process plants. Layout design determines how all equipment and/or structures in a chemical process plant are spatial arranged with their associated interconnections. A good layout design provides a healthy balance of efficient, safe and economic plant construction, operation, use of space and compliance with relevant laws, codes and standards, amongst other factors (Moran, 2017).

Each of these factors has, one way or the other, been incorporated over the years in mixed integer (non)linear programming $(\mathrm{MI}(\mathrm{N}) \mathrm{LP})$ models in a bid to obtain optimal layout designs for any given process plant. Penteado and Ciric (1996) focused on an optimal layout design that balanced safety and economics. The proposed MINLP model minimised overall costs for piping, land, financial risk and the installation of protection devices for a single floor layout. Financial risk was estimated based on the expected financial losses associated with the severity and probability of an accident. Georgiadis and Macchietto (1997) proposed an MILP formulation discretising the floor area with considerations for connection, floor construction and pumping costs. The model handled multi-floor floor layout and a heuristic was also proposed for large-sized problems. The heuristic selected units based on their degree of connectivity, starting with the first two units being fixed at a central location and iteratively solving for an additional unit until all were allocated. The limitations of the space discretisation approach by Georgiadis and Macchietto (1997) was addressed by Papageorgiou and Rotstein (1998) in a continuous space MILP model but for a single floor layout. The authors also considered the pre-allocation of equipment items to production sections. Further work was done by Barbosa-Póvoa et al. (2002) for multi-floor scenarios having irregularly shaped equipment items, multiple input and output connection points, variable number of floors with variable floor heights in 3-dimensional space. Irregular equipment items were modelled as a combination of a predefined number of rectangular objects. Patsiatzis and Papageorgiou (2002) further included area-dependent land purchase and floor construction costs for 3-dimensional layouts in an MILP model. Guirardello and Swaney (2005) included the feature of pipe routing and pipe layout, and Patsiatzis et al. (2005) investigated the layout aspects of pipeless batch plant. Additional safety considerations have also been included in the layout model over and above the minimum separation distances earlier adopted. Principles from the Dow's fire and explosion index guide (American Institute of Chemical Engineers, 1994) were incorporated into an MILP model by Patsiatzis et al. (2004) in estimating risk levels within a plant, and more recently, the Domino Hazard index has also been adopted to model potential hazardous events that can be mitigated with proper layout considerations (Brunoro Ahumada et al., 2018, de Lira-Flores et al., 2014, López-Molina et al., 2013, Tugnoli et al., 2008). In the later case, the domino effect of hazardous scenarios such as flash fire, fireball, pool and jet fires, and explosions were formulated as an MINLP (LópezMolina et al., 2013, de Lira-Flores et al., 2014) or MILP (Brunoro Ahumada 
et al., 2018) model, with an overall objective to minimize the total layout costs, damage costs and purchase of protection devices.

In recent times, owing to problems of scalability, heuristics, the use of evolutionary techniques and the combination of both have been developed for the layout problem. Previous simultaneous approaches were only able to solve layout problems having less than 11 units in reasonable computational times. Decomposition approaches (Patsiatzis and Papageorgiou, 2003), constructionbased methods (Xu and Papageorgiou, 2007) with improvement phases (Xu and Papageorgiou, 2009), and a number of evolutionary methods (Furuholmen et al., 2010, Kheirkhah et al., 2015, Nabavi et al., 2016, Park and Lee, 2015) have successfully addressed large-sized layout problems in shorter times, but globally optimal solutions are not guaranteed. Recently, more efficient multi-floor layout models were developed by Ejeh et al. (2018a) incorporating connection, pumping, area-dependent land and floor construction costs in the layout design of process plants having tall equipment. Each of the models was able to address a larger number of equipment items of up to 17 units simultaneously. The models were also extended to account for production sections within the process plant (Ejeh et al., 2018b). This work seeks to build on such existing models with the inclusion of additional features. The proposed model simultaneously obtains the layout of a given chemical process plant considering connection costs, vertical and horizontal pumping costs, area-dependent floor construction and land purchase costs, having tall equipment with design-specified heights for connection between equipment items. Constraints are further included in the proposed model to allow tall equipment items to extend a great deal above the top-most available floor. This feature has been non-existent in previous multi-floor layout models and restricted tall equipment items to only some of the available floors in the final solutions. Previous models also had an inherent lower bound on the number of floors that could be made available for layout design when tall equipment items were involved - the available number of floors being greater than or equal to the maximum number of floors required by the tallest equipment item. As such, the proposed model seeks to remove these restrictions. This will allow for the available number of floors to take any value from 1 to whatever number as deemed allowable for the layout design. These new features present a potential cost saving as well as increased flexibility to the decision maker on the final layout design. Some additional features considered in the literature, such as irregular shapes (Barbosa-Póvoa et al., 2002), piping layout (Guirardello and Swaney, 2005), could easily be accommodated using existing constraints from previous works. Integer cuts are also proposed in this work to improve solution efficiency, and results of the proposed model are compared with existing literature models.

In the remaining part of this paper, section 2 describes the multi-floor layout problem to be solved; the proposed model is described in section 3; and case studies are presented in section 4 to show the model performance, its new features and how it compares to previous models. Finally, concluding remarks of the major findings are highlighted in section 5 . 


\section{Problem Description}

The solution of the multi-floor process plant layout problem gives the optimal spatial arrangement of process plant equipment items within an available land area. Provision is also made for placement of equipment items in an optimal number of floors, considering interactions between equipment items. These interactions refer to interconnections by pipes, material transfers and minimum separation distances for safety considerations if specified. In this work, tall equipment items are also factored in. These equipment items, having heights greater than the specified floor height, are allowed to extend through consecutive floors. Furthermore, these tall equipment items can extend well beyond the top-most available floor if deemed optimal. The overall solution to the problem determines the minimum land area for the layout, floor construction cost, interconnection costs and pumping costs.

The problem is fully described as follows:

Given:

- a set of process units and their dimensions (length, depth and height);

- a set of potential floors available for layout;

- connectivity network amongst process units;

- cost data (connection, pumping, land, and construction);

- height between floors constructed;

- space and unit allocation limitations;

- minimum safety distances between process units;

to determine:

- total number of required floors for the layout;

- base land area occupied;

- area of floors;

- equipment-floor allocation;

so as to: minimise the total plant layout cost associated with connection, pumping, land purchase and floor construction.

The following assumptions are made:

- The geometries of all process plant equipment are approximated as rectangles.

- Distances between equipment items are rectilinear from their geometrical centres in the $\mathrm{x}-\mathrm{y}$ plane. Vertical distances are taken from a designspecified height on the equipment unique to each case study. 
- Equipment items can be rotated $90^{\circ}$ in the $x-y$ plane but must start from the base of the floor they are assigned.

- Any equipment item with a height greater than the floor height is allowed to extend through consecutive floors.

- Any equipment item can extend well above the top-most available floor.

\section{Mathematical Formulation}

\section{Nomenclature}

Indices

$\theta \quad$ floor count index

$i, j, n$ equipment item

$k \quad$ floor number

$s \quad$ rectangular area sizes

Sets

$K \quad$ set of potential floors

$M F \quad$ set of multi-floor equipment

\section{Parameters}

\begin{tabular}{|c|c|}
\hline$\alpha_{i}, \beta_{i}, \gamma_{i}$ & dimensions of equipment item $i$ \\
\hline$\delta_{i \theta}$ & 1 for equipment item $i$ if $\theta \leq M_{i}$; 0 otherwise \\
\hline$B M$ & a large number \\
\hline$C_{i j}^{c}$ & connection costs between items $i$ and $j$ \\
\hline$C_{i j}^{h}$ & horizontal pumping costs between items $i$ and $j$ \\
\hline & vertical pumping costs between items $i$ and $j$ \\
\hline$D e_{i j}^{\min }$ & minimum safety distance between items $i$ and $j$ \\
\hline$f_{i j}$ & $\begin{array}{l}1 \text { if flow direction between equipment items } i \text { and } j \text { is positive; } \\
0 \text {, otherwise }\end{array}$ \\
\hline$F C 1$ & fixed floor construction cost \\
\hline$F C 2$ & area-dependent floor construction cost \\
\hline FH & floor height \\
\hline$I P_{i j}$ & $\begin{array}{l}\text { distance between the base and input point on item } j \text { for the } \\
\text { connection between items } i \text { and } j\end{array}$ \\
\hline$L C$ & area-dependent land purchase cost \\
\hline$M_{i}$ & number of floors required by equipment item $i$ \\
\hline$O P_{i j}$ & $\begin{array}{l}\text { distance between the base and output point on equipment } i \\
\text { for the connection between items } i \text { and } j\end{array}$ \\
\hline $\bar{Y}$ & y dimensions of pre-defined rectangular area sizes $s$ \\
\hline
\end{tabular}


Integer variable

NF number of floors

Binary variables

$E 1_{i j}, E 2_{i j} \quad$ non-overlapping binary, a set of values which prevents equipment overlap in one direction in the $\mathrm{x}-\mathrm{y}$ plane

$N_{i j} \quad 1$ if items $i$ and $j$ are assigned to the same floor; 0 , otherwise

$O_{i} \quad 1$ if length of item $i$ is equal to $\alpha_{i} ; 0$, otherwise

$Q_{s} \quad 1$ if rectangular area $s$ is selected for the layout; 0 , otherwise

$S_{i k}^{s} \quad 1$ if item $i$ begins on floor $k ; 0$, otherwise

$V_{i k} \quad 1$ if item $i$ is assigned to floor $k$

$W_{k} \quad 1$ if floor $k$ is occupied; 0 , otherwise

Continuous variables

$\omega_{i} \quad$ number of floors by which a multi-floor item $i \in M F$ extends over the topmost floor

$A_{i j} \quad$ relative distance in y coordinates between items $i$ and $j$, if $i$ is above $j$

$A R_{s} \quad$ predefined rectangular floor area $s$

$B_{i j} \quad$ relative distance in y coordinates between items $i$ and $j$, if $i$ is below $j$

$d_{i} \quad$ breadth of item $i$

$D_{i j} \quad$ relative distance in z coordinates between items $i$ and $j$, if $i$ is lower than $j$

FA base land area

$l_{i} \quad$ length of item $i$

$L_{i j} \quad$ relative distance in $\mathrm{x}$ coordinates between items $i$ and $j$, if $i$ is to the left of $j$

$N Q_{s} \quad$ linearisation variable expressing the product of $N F$ and $Q_{s}$

$R_{i j} \quad$ relative distance in x coordinates between items $i$ and $j$, if $i$ is to the right of $j$

$T D_{i j} \quad$ total rectilinear distance between items $i$ and $j$

$U_{i j} \quad$ relative distance in $\mathrm{z}$ coordinates between items $i$ and $j$, if $i$ is higher than $j$

$x_{i}, y_{i} \quad \mathrm{x}, \mathrm{y}$ coordinates of the geometrical centre of item $i$

$X^{\max }, Y^{\max }$ dimensions of base land area

In this section, the proposed MILP model for the multi-floor process plant layout problem is presented. The proposed model is extended from our previous work, Models A.1 - A.3 in Ejeh et al. (2018b), whose details are given in the Appendix A. Constraints for equipment floor assignment, tall/ multi-floor equipment representation, interconnection distances and floor area calculations, and others are described. A key difference in the proposed model is in its ability 
to allow for a greater range of values for the available number of floors, particularly values less than the number of floors required by the tallest unit in a plant which was not possible in previous models. Equipment items are also allowed to extend above the top-most available floor. Also, a reformulation of how multifloor equipment items are modelled is included - with inspiration drawn from the utility availability constraints in discrete time scheduling of batch plants (Kondili et al., 1993).

\subsection{Multi-floor equipment constraints}

In order for equipment items requiring more than one floor to span across successive floors, the constraints below are introduced:

$$
V_{i k}=\sum_{\theta=1}^{M_{i}} \delta_{i \theta} \cdot S_{i, k-\theta+1}^{s} \quad \forall i, k
$$

where $V_{i k}$ is a binary variable which determines if an equipment $i$ is assigned to floor $k$ and $\delta_{i \theta}=1$ for all $\theta \leq M_{i}$. $S_{i k}^{s}$ is a binary variable which determines if an equipment item $i$ starts at floor $k$. This should only occur on one floor:

$$
\sum_{k} S_{i k}^{s}=1 \quad \forall i
$$

These constraints also ensure tall units occupy consecutive floors.

\subsection{Floor constraints}

Every non-multi-floor equipment $i$ available should be assigned to one floor:

$$
\sum_{k} V_{i k}=1 \quad \forall i \notin M F
$$

For tall/multi-floor equipment items $(i \in M F)$, to ensure that they can extend well above the top-most floor if required, such constraint is written as:

$$
\sum_{k} V_{i k}=M_{i}-\omega_{i} \quad \forall i \in M F
$$

where:

$$
\omega_{i} \geq \sum_{k} k \cdot S_{i k}^{s}+M_{i}-|K|-1 \quad \forall i \in M F
$$

$\omega_{i}$ represents the number of floors by which a multi-floor equipment item $i$ extends over the top-most floor. This allows the potential/available number of floors for the layout design to be less than the maximum number of floors required by any equipment item if necessary.

A variable, $N_{i j}$, is introduced to determine if equipment $i$ and $j$ occupy the same floor (Ejeh et al., 2018b):

$$
N_{i j} \geq V_{i k}+V_{j k}-1 \quad \forall i, j>i, k
$$


The variable $N_{i j}$ takes the value of 1 if and only if items $i$ and $j$ are on any same floor.

Furthermore, a floor must exist if an equipment starts on it:

$$
S_{i k}^{s} \leq W_{k} \quad \forall i, k
$$

or the floor above it is also occupied:

$$
W_{k} \leq W_{k-1} \quad \forall k>1
$$

The minimum number of floors required is then given by:

$$
N F \geq \sum_{k} W_{k}
$$

\subsection{Objective function}

The objective function minimises the total connection cost, pumping cost, land area cost, floor construction cost and floor-area dependent cost:

$$
\begin{array}{r}
\min \sum_{i} \sum_{j \neq i: f_{i j}=1}\left[C_{i j}^{c} T D_{i j}+C_{i j}^{v} D_{i j}+C_{i j}^{h}\left(R_{i j}+L_{i j}+A_{i j}+B_{i j}\right)\right] \\
+F C 1 \cdot N F+F C 2 \sum_{s} A R_{s} \cdot N Q_{s}+L C \cdot F A
\end{array}
$$

subject to equations (1) - (9), and (S.6), (S.7), (S.13) - (S.32) in Appendix A. This constitutes model OPTL.

\subsection{Integer cut}

The following integer cuts were applied to the model to reduce the solution space:

$$
\begin{array}{rlrl}
\frac{E 1_{i n}+E 2_{i n}}{2} & \geq E 1_{i j}+E 2_{i j}+E 1_{j n}+E 2_{j n}-3 & \forall i<j<n \\
N_{i j} & \geq E 1_{i j} \quad \forall i, j>i \\
N_{i j} & \geq E 2_{i j} \quad \forall i, j>i
\end{array}
$$

Given an equipment item trio $i, j, n$, where item $i$ is strictly below $j$, and $j$ is strictly below $n$, equation (11) prevents the non-overlapping constraints in equations (S.13) - (S.16) from considering the impractical configuration where $n$ is below $i$. This is achieved as when the RHS of equation (11) is equal to 1 (corresponding to $i$ being strictly below $j$ and $j$ strictly below $n$ ), the LHS is forced to 1 (corresponding to $i$ being strictly below $n$ ). Equations (12) and (13), force the non-overlapping binary variables $E 1_{i j}$ and $E 2_{i j}$ to zero if two items $i$ and $j$ are on different floors.

The inclusion of equations (11) - (13) in model OPTL constitutes model OPTL_IC. 


\section{Case Studies}

Four examples were applied to the proposed model OPTL with and without integer cuts using GAMS (GAMS Development Corporation, 2018) modelling system v25.0.2 and CPLEX v12.8.0.0 solver on an Intel ${ }^{\circledR}$ Xeon ${ }^{\circledR}$ E5-1650 CPU using 12 threads with $32 \mathrm{~GB}$ RAM. Each run was solved to global optimality, or a CPU limit of $10,000 \mathrm{~s}$. The total number of units in each example ranged from $8-25$ to show model capabilities and limits. With exception of the Urea production plant where 5 alternative sizes $(5-45 \mathrm{~m}$, with a step size of $10 \mathrm{~m})$ was used for the floor area, twelve sizes were used for all the examples $(5-60 \mathrm{~m}$, with a step size of $5 \mathrm{~m})$. The $B M$ values used in each example was defined as:

$$
B M=\max _{s}\left(\bar{X}_{s}, \bar{Y}_{s}\right)+\max _{i, j}\left(D e_{i j}^{\min }\right)
$$

which is the sum of the maximum allowable length or breadth of the predefined area dimensions, and the minimum separation distance. This removes any restriction on the position coordinates of an item by the inactive non-overlapping constraints of equations (S.13) - (S.16), and prevent feasible regions being enlarged unnecessarily.

The examples are described below with additional information provided in appendix B:

- The first example is an Urea production plant (Figure 1) having a total of 8 units (Ejeh et al., 2018a). 2 units (2 and 4) exceed the floor height of $8 \mathrm{~m}$ and each equipment item must be separated from every other by at least $4 \mathrm{~m}$;

- The second example is a Crude distillation plant with pre-heating train (CDU plant) consisting of 17 units (Ejeh et al., 2018b). Figure 2 shows the process flow diagram of the plant. 5 units have an equipment height greater than the floor height of $5 \mathrm{~m}$ and will need to extend through floors. No minimum separation distance is enforced for this case study and 7 potential floors are available for layout design.

- The next example is a liquefied natural gas liquefaction (LNG) plant (Figure 3) with 22 units (Hwang and Lee, 2014), 6 of which exceed the floor height of $8 \mathrm{~m}$. A minimum distance between each equipment item of $4 \mathrm{~m}$ is required, with item 16 (MR compressor) directly above item 17 (MR compressor cooler) and below item 18 (MR overhead crane); and item 3 (PMR compressor) directly above item 4 (PMR cooler) and below item 5 (PMR overhead crane). $50 \%$ of the area at the ground floor and $60 \%$ at the topmost floor need to be free as a workspace area and emergency area respectively. Additional constraints as described in Ejeh et al. (2018b) are included to represent these considerations.

- The final example is a Crude oil \& gas processing (COGP) plant (Figure 4) consisting of 25 units adapted from $\mathrm{Xu}$ and Papageorgiou (2009). A total of 9 units - all 8 Contactors and the Separator - have heights greater than the floor height of $5 \mathrm{~m}$, and 7 floors are made available for layout. 


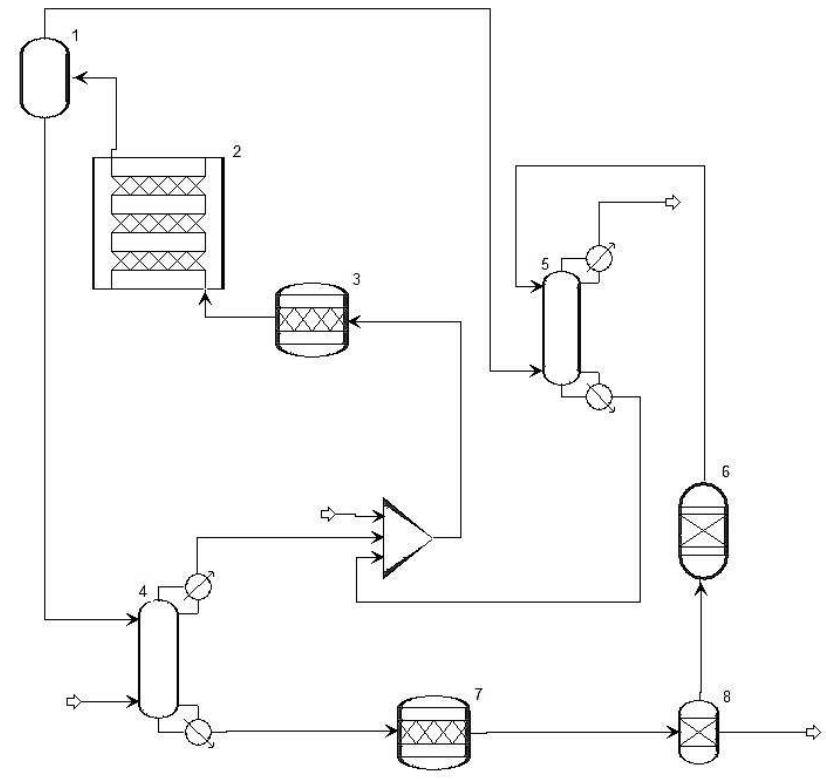

Figure 1: Flow diagram of Urea Production Plant (See Table B.1 in Appendix B for a description of the equipment item label)

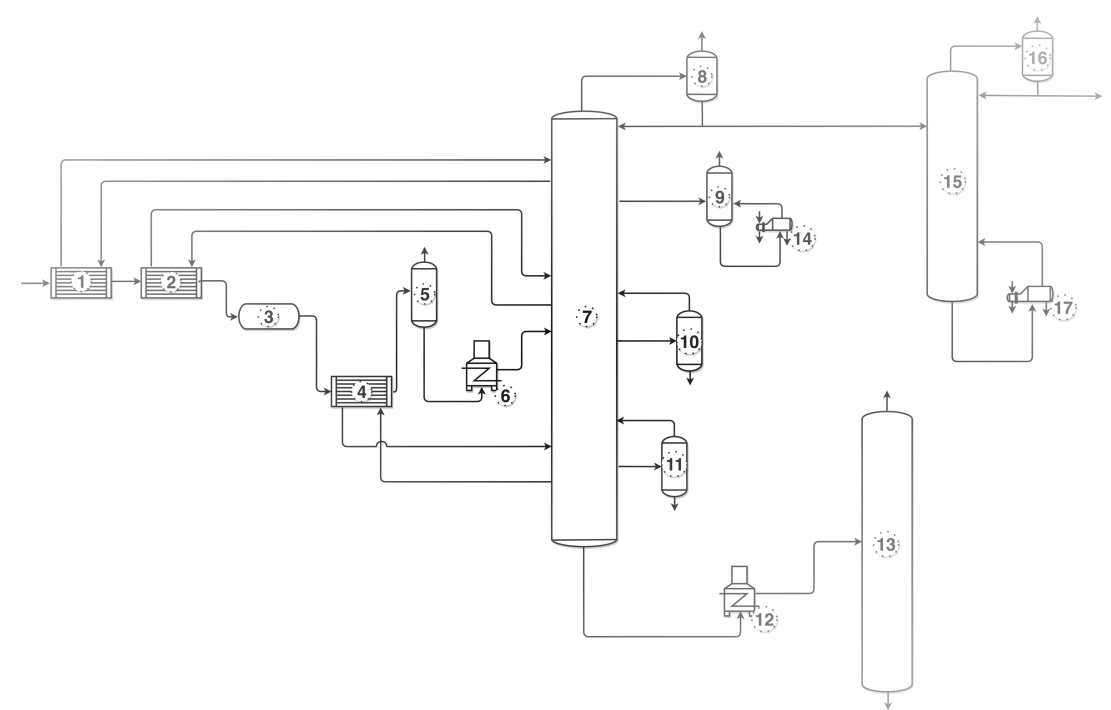

Figure 2: Flow diagram of Crude distillation (CDU) Plant (See Table B.3 in Appendix B for a description of the equipment item label) 


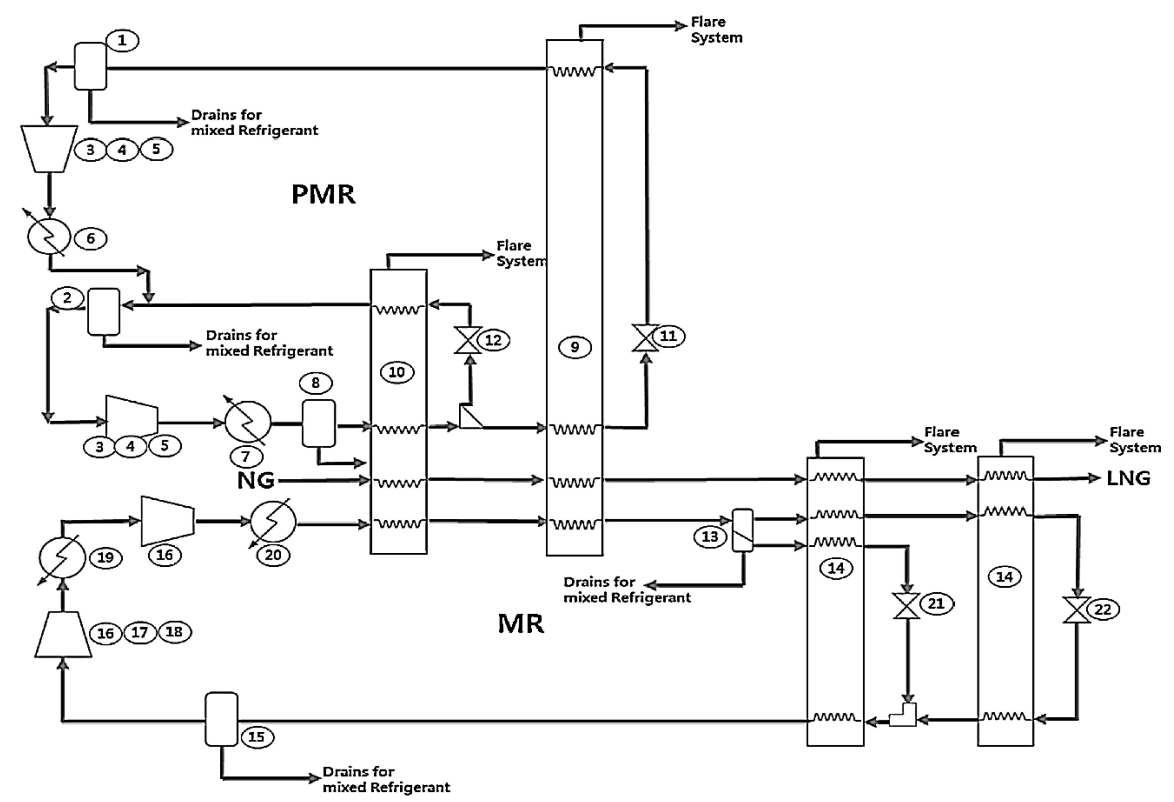

Figure 3: Flow diagram of Liquefied natural gas (LNG) plant (See Table B.5 in Appendix B for a description of the equipment item label)

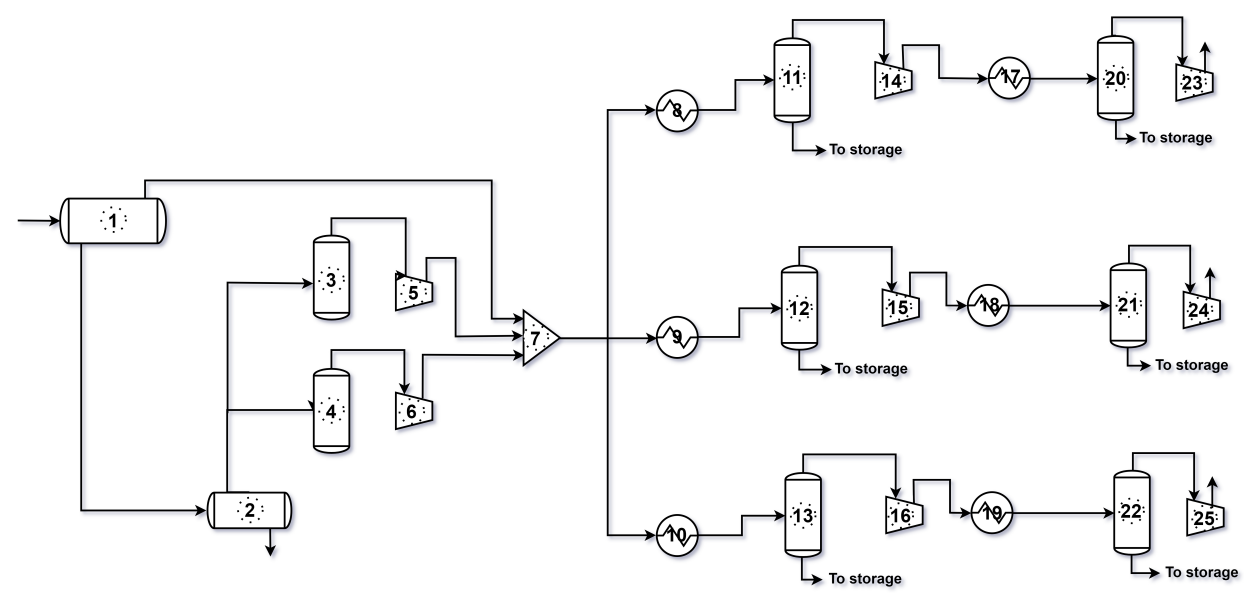

Figure 4: Flow diagram of Crude oil \& gas processing (COGP) plant (See Table B.7 in Appendix B for a description of the equipment item label)

Table 1 shows the computational results and model statistics of the proposed models for each of the examples presented. Figures $5-8$ show the plan and 3- 
dimensional views of the optimal/best layouts obtained for each example. Each of the $3 \mathrm{D}$ views are drawn from a direction that shows most of the equipment items for the case study being considered.

Table 1: Model Statistics \& computational performance

\begin{tabular}{cccccc} 
Model & Total Cost (rmu) & CPU (s) & Eqns $^{1}$ & Cts_var $^{2}$ & Dis_var $^{3}$ \\
\hline \hline \multicolumn{7}{c}{ Urea plant - 8 units } \\
\hline OPTL & $117,431.0$ & 1.6 & 431 & 193 & 118 \\
OPTL_IC & $117,431.0$ & 0.6 & 543 & 193 & 118 \\
\hline \hline \multicolumn{7}{c}{ CDU plant - 17 units } \\
\hline OPTL & $592,322.2$ & $1,678.1$ & 2,150 & 679 & 551 \\
OPTL_IC & $592,322.2$ & 131.6 & 3,102 & 679 & 551 \\
\hline \hline \multicolumn{7}{c}{ LNG plant - 22 units } \\
\hline OPTL & $1,466,654.2$ & $(2.8 \%)^{4}$ & 2,784 \\
OPTL_IC & $1,466,654.2$ & $(2.2 \%)^{4}$ & 4,786 & 786 & 736 \\
\hline \hline \multicolumn{7}{c}{ COGP plant - 25 units } \\
\hline OPTL & $269,310.5$ & $(17.0 \%)^{4}$ & 4,122 \\
OPTL_IC & $255,320.4$ & $(11.8 \%)^{4}$ & 7,022 & 914 \\
\hline \hline
\end{tabular}

\footnotetext{
${ }^{1}$ Eqns - No. of equations $\quad{ }^{2}$ Cts_var - No. of continuous variables

${ }^{3}$ Dis_var - No. of discrete variables $\quad{ }^{4}$ Relative gap quoted at CPU limit of $10,000 \mathrm{~s}$

Relative gap $(\%)=\frac{\mid \text { Best estimated solution }- \text { Best integer solution } \mid}{\max (\text { Best estimated solution, Best integer solution })} \times 100$
}

The optimal layout for the Urea plant is shown in Figure 5. A total of 4 floors out of 4 made available were selected for the layout with an area of $5 \mathrm{~m}$ $\times 15 \mathrm{~m}$ and a total cost of $117,431.0 \mathrm{rmu}$. Units 2 and 4 each requiring 4 and 2 floors were positioned from the 1st and 2nd floors respectively. This is consistent with previously obtained results using Models A.1 - A.3 proposed by Ejeh et al. (2018a). However, the current model OPTL allows for additional flexibility to the decision maker as the choice of the number of potential/available floors can be less than the number of floors required by the tallest unit (4 floors), which was not possible in the previous models. Table 2 shows a sensitivity analysis of the globally optimal solution obtained by the current model OPTL and models A.1 - A.3, to the number of floors made available for layout in the Urea production plant. Although the tallest unit 2 required 4 floors, single floor layout solutions could still be obtained by model OPTL if required, unlike models A.1 - A.3. A more informed decision can then be made on the compromise between the total number of floors and the total layout cost. 
Table 2: Sensitivity analysis on the number of available floors for Urea production plant

\begin{tabular}{c|cccc}
\multicolumn{2}{c}{$\begin{array}{c}\text { Available } \\
\text { floors, }|K|\end{array}$} & \multicolumn{2}{c}{ Model OPTL } & \multicolumn{2}{c}{ Models A.1 - A.3 } \\
& Total Cost $(\mathrm{rmu})$ & $N F$ & Total Cost (rmu) \\
\hline 1 & 1 & $260,942.2$ & - & $-{ }^{1}$ \\
2 & 2 & $167,298.8$ & - & -1 \\
3 & 3 & $149,498.0$ & - & $-^{1}$ \\
4 & 4 & $117,431.0$ & 4 & $117,431.0$ \\
\hline
\end{tabular}

${ }^{1}$ Infeasible model 

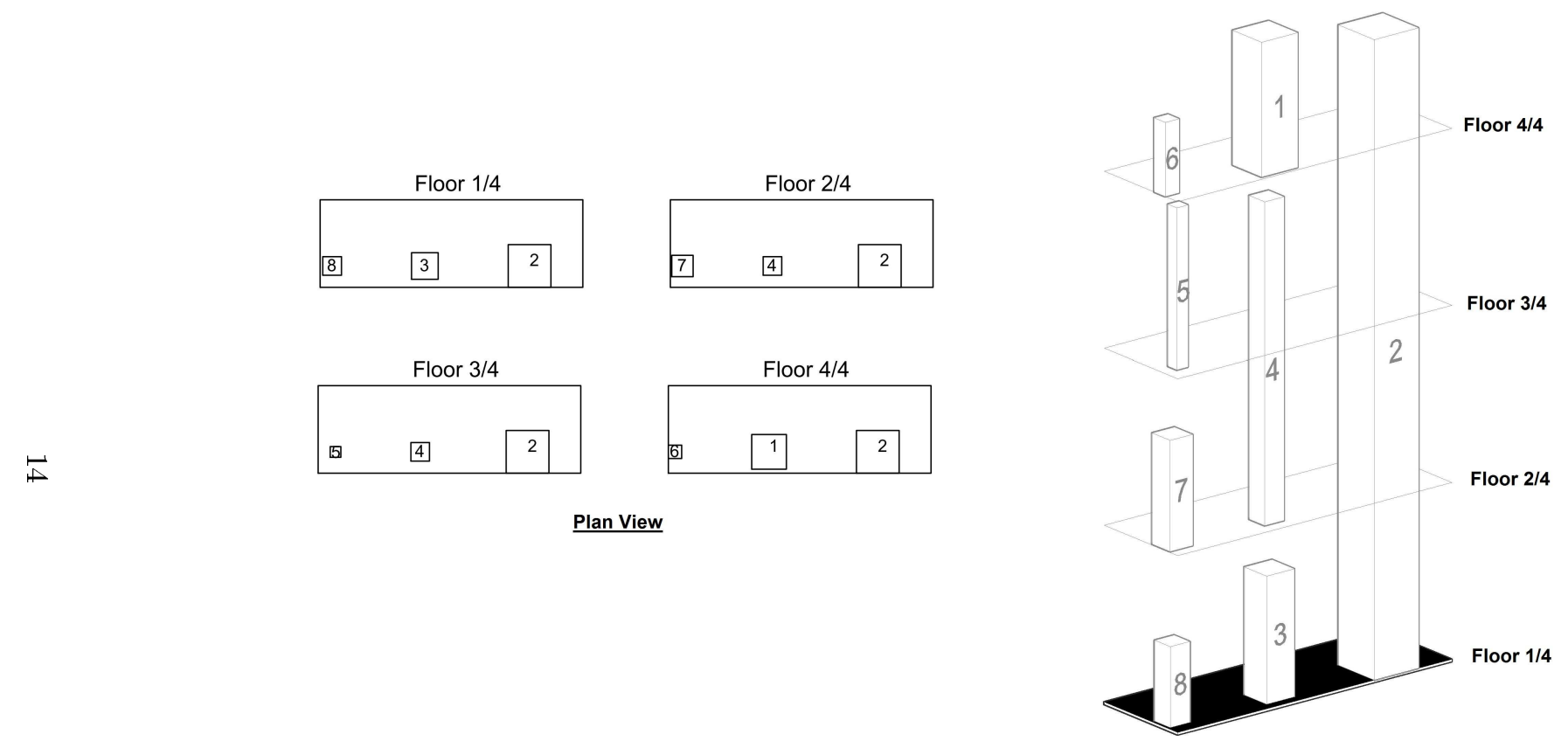

3D South-West View

Figure 5: Optimal layout for Urea production plant 
The layout results (plan and 3D view) for the CDU plant is shown in Figure 6. A total of 7 floors were selected with an area of $20 \mathrm{~m} \times 15 \mathrm{~m}$ and a total cost of $592,322.2 \mathrm{rmu}$. The total cost is about $2 \%$ less than the globally optimal value obtained in previous models A.1 - A.3 in Ejeh et al. (2018b). This cost savings is majorly attributed to the fact that the proposed model allows multi-floor equipment items extend well above the total number of floors made available and/or selected. Particularly, unit 6 requiring 4 floors was assigned only floors 5, 6 and 7, and extended beyond the 7 available floors. Table 3 also shows the results of a sensitivity analysis on the number of available floors used in models OPTL and A.1 - A.3. In each of the cases shown, all models were solved to global optimality without a time restriction. The tallest unit in the CDU example requires 5 floors, hence models A.1 - A.3 could not solve the problem for any number of available floors less than 5 . The proposed model also obtained the same or better solutions than previous models for each run. For 5 available floors, although each of models OPTL and A.1 - A.3 selected 5 total floors, model OPTL obtained a smaller objective value than A.1 - A.3. A similar result was obtained with 6 and 7 available floors. This was achieved by leveraging the feature where tall units were allowed by model OPTL to extend above the floors made available. This can bring about cost savings especially where there are no restrictions to equipment floor positions or the maximum height of the process plant. The proposed model can also restrict equipment positioning only to the available number of floors as in models A.1 - A.3. This can be achieved by fixing the value of $\omega_{i}$ to 0 . 

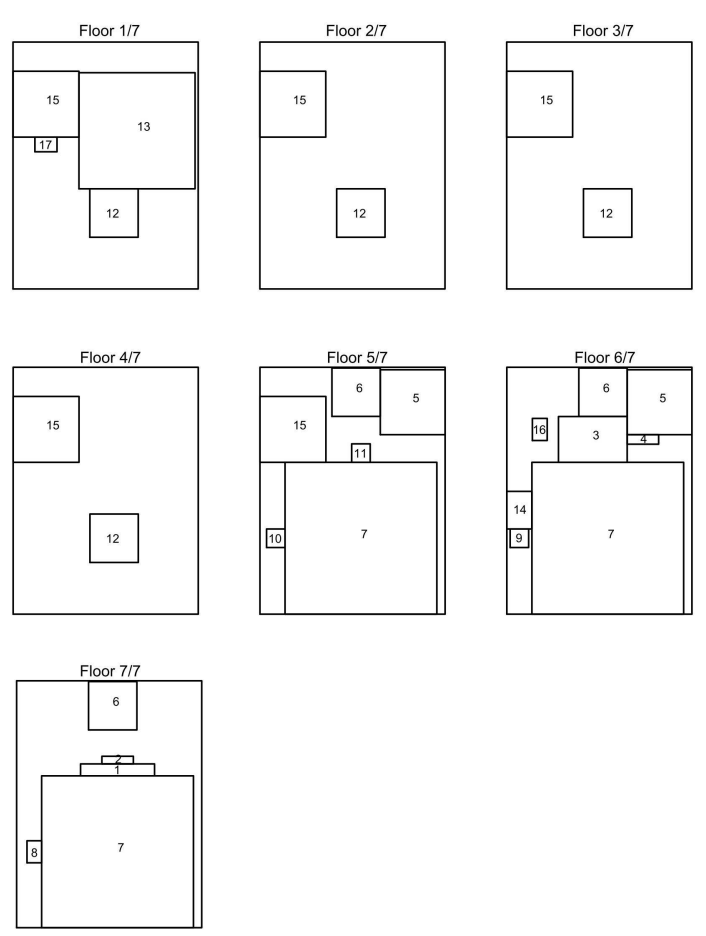

Plan View

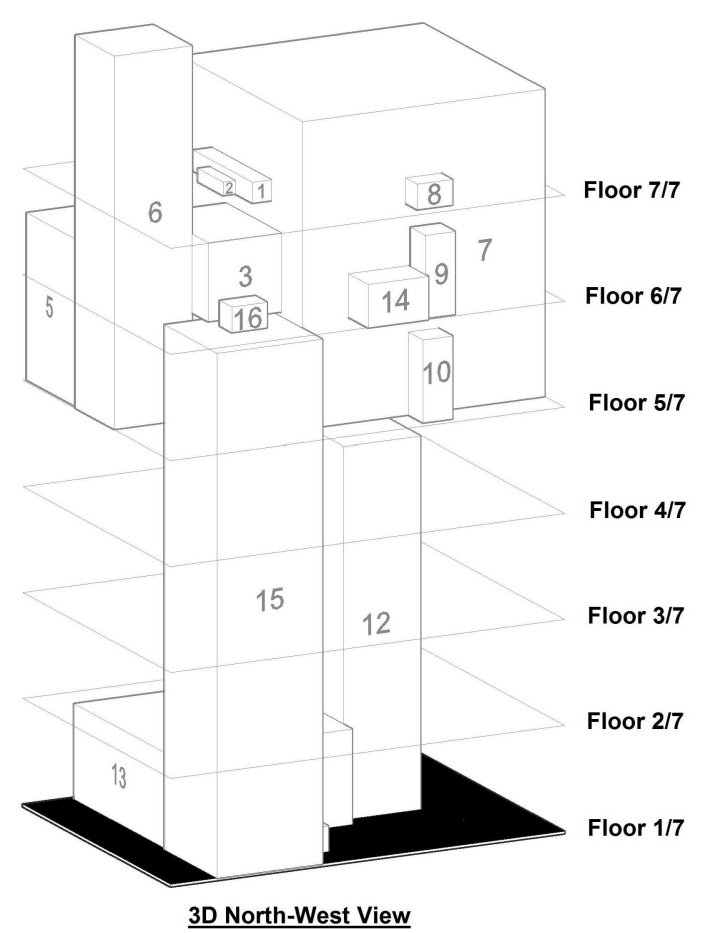

Figure 6: Best obtained layout for CDU plant 
Table 3: Sensitivity analysis on the number of available floors for CDU plant

\begin{tabular}{ccccc}
\multicolumn{2}{c}{ Available } & \multicolumn{2}{c}{ Model OPTL } & \multicolumn{2}{c}{ Models A.1 - A.3 } \\
floors, $|K|$ & $N F$ & Total Cost (rmu) & NF & Total Cost (rmu) \\
\hline 1 & 1 & $1,112,094.7$ & - & -1 \\
2 & 2 & $855,465.8$ & - & -1 \\
3 & 3 & $697,672.4$ & - & -1 \\
4 & 4 & $624,452.8$ & - & -1 \\
5 & 5 & $603,886.5$ & 5 & $614,820.0$ \\
6 & 5 & $603,886.5$ & 5 & $614,820.0$ \\
7 & 7 & $592,322.2$ & 5 & $603,886.5$ \\
\hline
\end{tabular}

${ }^{1}$ Infeasible model

The layout results of the much larger chemical plants - LNG and COGP - having 22 and 25 units are shown in Figures 7 and 8 respectively. For the LNG plant, a total cost of 1,466,654.2 rmu was obtained with 5 floors selected measuring $35 \mathrm{~m} \times 30 \mathrm{~m}$. None of the multi-floor equipment items extended well above the top-most floor and all additional considerations for the plant were addressed in the solution obtained. A total cost of 269,310.5 rmu was realised for the COGP plant having 7 floors with a floor are of $20 \mathrm{~m} \times 10 \mathrm{~m}$. 

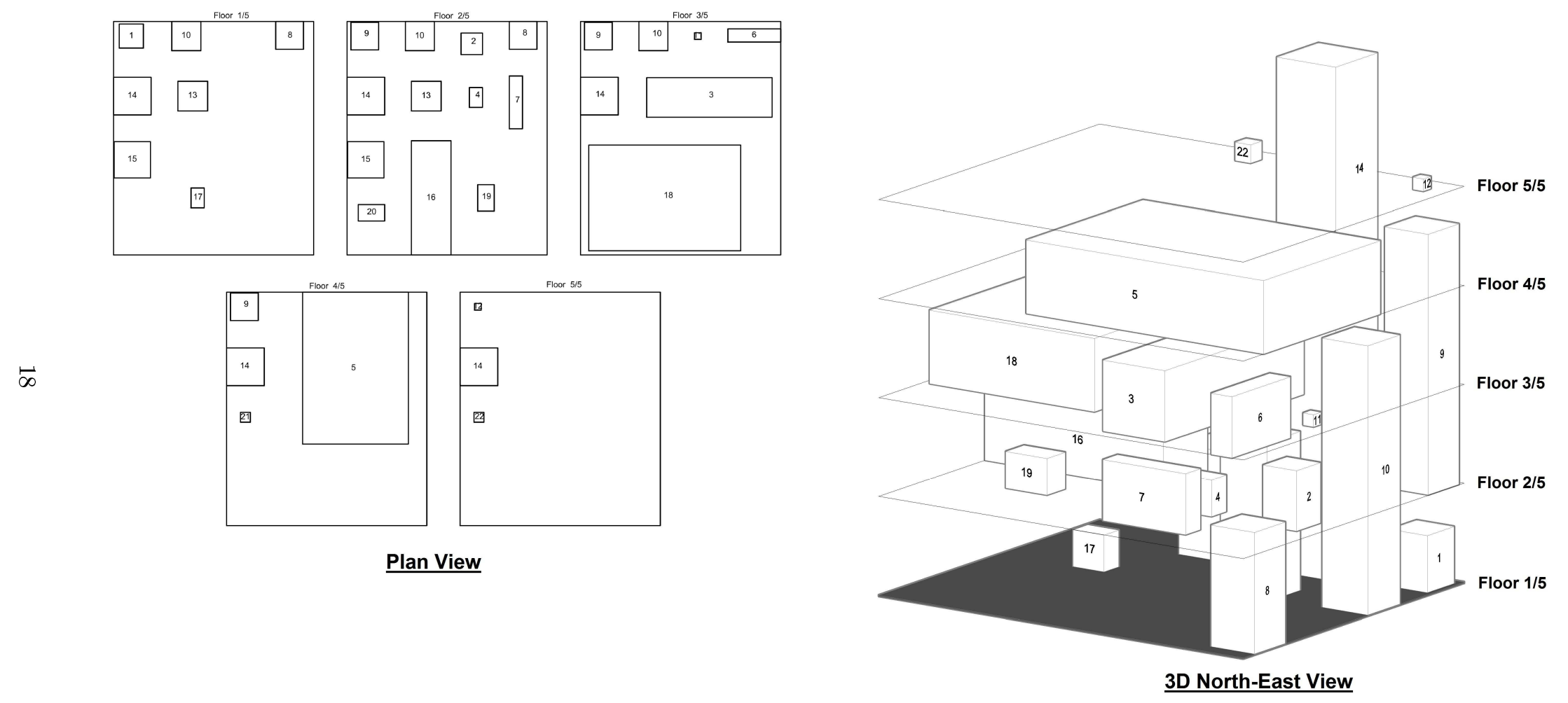

Figure 7: Best obtained layout for LNG plant 

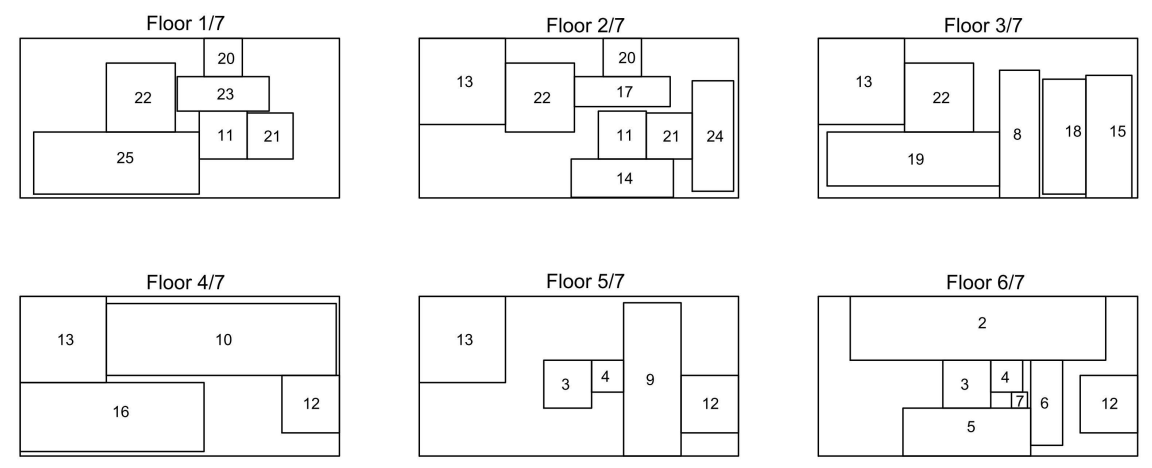

$\vec{\sigma}$

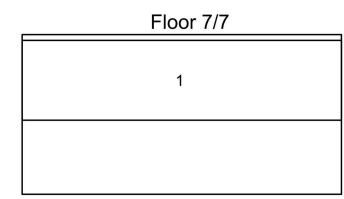

$\underline{\text { Plan View }}$

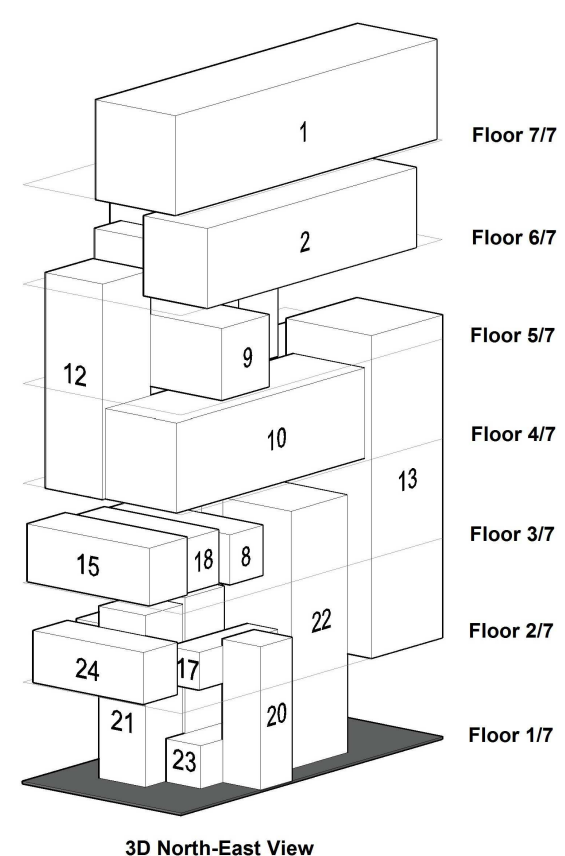

Figure 8: Best obtained layout for COGP plant 
Both the LNG and COGP plant examples did not solve to global optimality within the CPU limit of 10,000 s. However, including the integer cuts to the proposed model brought about a better solution and/or smaller relative gap. Total cost reduction by as much as $5 \%$ was achieved for the COGP plant. Computational time savings were also obtained for the Urea and CDU plant by up to $1100 \%$ in the latter case. Figure 9 shows a plot of the integer solution progress with time for each of the examples considered using CPLEX solver. In all cases considered, the proposed model showed a better performance with the inclusion of the integer cut. For the Urea production plant where the global optimum was obtained within the set time limit, model OPTL_IC found the solution at an earlier time. Although this was not the case for the CDU plant, model OPTL_IC closed the gap to the final solution at a much faster time. For the larger examples, the inclusion of the integer cut gave better solutions a great part of the period of the entire solve.
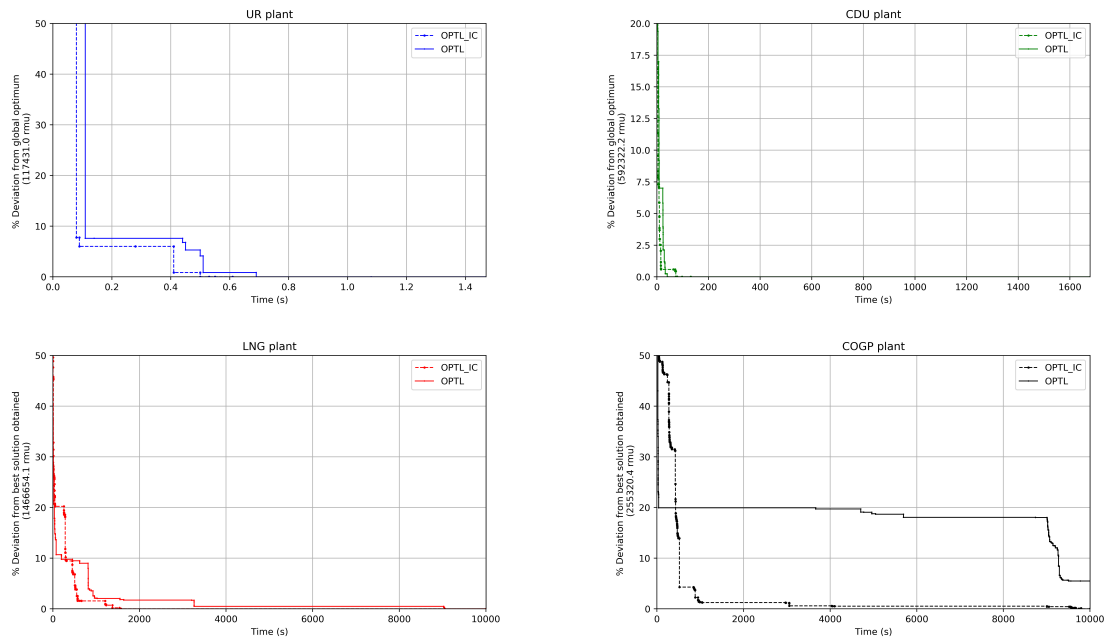

Figure 9: Integer solution progress of model OPTL with and without integer cuts

\section{Concluding remarks}

In this work, a new MILP model was proposed to address the multi-floor process plant layout problem. The proposed model, OPTL, minimises the total layout cost attributed to the installation of pipes, pumping of process fluids, area-dependent construction of floors and land purchase, considering tall equipment spanning consecutive floors, with additional features which allows multifloor equipment items span well above the maximum available number of floors. The proposed model also allows for the available number of floors to be less than the maximum number of floors required by any multi-floor equipment item in 
the plant. Integer cuts were further included to improve the computational efficiency of the model by eliminating unrealistic layout scenarios and restricting certain binary variable values. Model computational performance and limits were demonstrated with four industry-relevant case studies having a total of 8 - 25 units, and results compared with existing multi-floor layout models with similar considerations (Ejeh et al., 2018a;b). The case studies included an 8unit Urea production plant, a 17-unit crude distillation (CDU) plant, a liquefied natural gas (LNG) plant having 22 units and a Crude oil \& gas processing plant with 25 units. Each of these plants had units with height greater than the standard floor height for each plant.

Results showed that model OPTL successfully handled the unique layout considerations of each case study. The proposed model was able to achieve same or better solution than previously obtained from other models. It also presented more layout solution options to the decision maker based on the choice of the number of floors available. The inclusion of the integer cuts in model OPTL showed improvements on the solutions obtained, CPU and/or relative gap achieved at the set time limit in all examples considered.

Further work still needs to be carried out especially on alternative solution methods for larger examples similar to the construction-based approach (Xu and Papageorgiou, 2007) and the improvement-type algorithm (Xu and Papageorgiou, 2009). As a future work, solution algorithms will be investigated to obtain optimal solutions in reasonable computational times.

\section{Acknowledgement}

JOE gratefully acknowledges the Petroleum Technology Development Fund (PTDF), Nigeria. 


\section{Appendix A. MILP models for multi-floor process plant layout}

Models A.1 - A.3 proposed by Ejeh et al. (2018b) for cases without production sections are presented as follows:

\section{A.1. Model A.1}

\section{A.1.1. Floor constraints}

Floor constraints ensure that equipment items are assigned to an equivalent number of floors based on their height and that a floor exists only if an equipment item is placed on it:

$$
\begin{array}{rlrl}
\sum_{k} V_{i k} & =M_{i} & \forall i & \\
N_{i j} & \geq V_{i k}+V_{j k}-1 & \forall i, j>i \\
S_{i k}^{s} & \leq W_{k} & \forall i, k \\
W_{k} & \leq W_{k-1} & \forall k>1 ; \\
N F & \geq \sum_{k} W_{k} & \forall i
\end{array}
$$

\section{A.1.2. Equipment orientation constraints}

A $90^{\circ}$ rotation of equipment orientation is allowed in the $\mathrm{x}-\mathrm{y}$ plane.

$$
\begin{aligned}
l_{i} & =\alpha_{i} O_{i}+\beta_{i}\left(1-O_{i}\right) & & \forall i \\
d_{i} & =\alpha_{i}+\beta_{i}-l_{i} & & \forall i
\end{aligned}
$$

A.1.3. Multi-floor equipment constraints

Multi-floor equipment is modelled as follows:

$$
\begin{aligned}
& -V_{i k}+V_{i, k-1}+S_{i k}^{s} \geq 0 \quad \forall i, k \\
& -V_{i k}+V_{i, k+1}+S_{i k}^{f} \geq 0 \quad \forall i, k \\
& \sum_{k} S_{i k}^{s}=1 \quad \forall i \\
& \sum_{k} S_{i k}^{f}=1 \quad \forall i \\
& \sum_{k=k^{\prime}}^{k^{\prime}+M_{i}-1} V_{i k^{\prime}} \geq M_{i} . S_{i k}^{s} \quad \forall i, k
\end{aligned}
$$




\section{A.1.4. Non-overlapping constraints}

To prevent two or more equipment items occupying the same space within a floor, the following constraints are introduced:

$$
\begin{array}{ll}
x_{i}-x_{j}+B M\left(1-N_{i j}+E 1_{i j}+E 2_{i j}\right) \geq \frac{l_{i}+l_{j}}{2}+D e_{i j}^{m i n} & \forall i, j>i \\
x_{j}-x_{i}+B M\left(2-N_{i j}-E 1_{i j}+E 2_{i j}\right) \geq \frac{l_{i}+l_{j}}{2}+D e_{i j}^{m i n} & \forall i, j>i \\
y_{i}-y_{j}+B M\left(2-N_{i j}+E 1_{i j}-E 2_{i j}\right) \geq \frac{d_{i}+d_{j}}{2}+D e_{i j}^{m i n} & \forall i, j>i \\
y_{j}-y_{i}+B M\left(3-N_{i j}-E 1_{i j}-E 2_{i j}\right) \geq \frac{d_{i}+d_{j}}{2}+D e_{i j}^{\min } & \forall i, j>i
\end{array}
$$

\section{A.1.5. Distance constraints}

Distance constraints determine the relative distances in the $\mathrm{x}$ and $\mathrm{y}$ coordinates between connected equipment.

$$
\begin{array}{cc}
R_{i j}-L_{i j}=x_{i}-x_{j} & \forall i, j: f_{i j}=1 \\
A_{i j}-B_{i j}=y_{i}-y_{j} & \forall i, j: f_{i j}=1 \\
U_{i j}-D_{i j}=F H \sum_{k}(k-1)\left(S_{i k}^{s}-S_{j k}^{s}\right)+O P_{i j}-I P_{i j}
\end{array} \quad \forall i, j: f_{i j}=1
$$

\section{A.1.6. Area Constraints}

The area of each floor is as described by equations (S.21) - (S.26).

$$
\begin{gathered}
F A=\sum_{s} A R_{s} Q_{s} \\
\sum_{s} Q_{s}=1
\end{gathered}
$$

The floor length and depth is selected from the chosen rectangular area size dimensions:

$$
\begin{aligned}
X^{\max } & =\sum_{s} \bar{X}_{s} Q_{s} \\
Y^{\max } & =\sum_{s} \bar{Y}_{s} Q_{s} \\
N Q_{s} & \leq K \cdot Q_{s} \quad \forall s \\
N F & =\sum_{s} N Q_{s}
\end{aligned}
$$




\section{A.1.7. Layout design constraints}

Layout design constraints ensure that equipment items are placed within the boundaries of the floor area and start from the base of a floor.

$$
\begin{array}{cc}
x_{i} \geq \frac{l_{i}}{2} & \forall i \\
y_{i} \geq \frac{d_{i}}{2} & \forall i \\
x_{i}+\frac{l_{i}}{2} \leq X^{\text {max }} & \forall i \\
y_{i}+\frac{d_{i}}{2} \leq Y^{\text {max }} & \forall i
\end{array}
$$

\section{A.1.8. Symmetry breaking constraints}

Symmetry breaking constraints are introduced as follows:

$$
\begin{gathered}
x_{i}+y_{i}-x_{j}-y_{j} \geq \delta \cdot N_{i j} \quad \forall(i, j)=\underset{i, j \in M F}{\arg \max } C_{i j}^{c} \\
E 1_{i j}=0 \quad \forall(i, j)=\underset{i, j \in M F}{\arg \max } C_{i j}^{c}
\end{gathered}
$$

where $\delta=\min \left(\frac{l_{i}}{2}, \frac{d_{i}}{2}\right)+\min \left(\frac{l_{j}}{2}, \frac{d_{j}}{2}\right)$. These fix the relative position of $i$ to $j$. Units $i$ and $j$ are chosen as the two multi-floor units having the highest connection costs.

\section{A.1.9. Objective function}

$$
\begin{array}{r}
\min \sum_{i} \sum_{j \neq i: f_{i j}=1}\left[C_{i j}^{c} T D_{i j}+C_{i j}^{v} D_{i j}+C_{i j}^{h}\left(R_{i j}+L_{i j}+A_{i j}+B_{i j}\right)\right] \\
+F C 1 \cdot N F+F C 2 \sum_{s} A R_{s} \cdot N Q_{s}+L C \cdot F A
\end{array}
$$

subject to (S.1) - (S.32).

\section{A.2. Model A.2}

Model A.2 has the same formulation as A.1 with the exception that equations (S.9), (S.11) and (S.12) are replaced by (S.34) below:

$$
\sum_{\theta=1}^{M_{i}-1} V_{i, k+\theta} \geq\left(M_{i}-1\right) .\left(V_{i k}-V_{i, k-1}\right) \quad \forall i, k
$$

\section{A.3. Model A.3}

For Model A.3, equations (S.8), (S.9) and (S.12) in model A.1 are replaced by (S.35) below:

$$
V_{i k}-V_{i, k-1}=S_{i k}^{s}-S_{i, k-1}^{f} \quad \forall i, k
$$




\section{Appendix B. Data for case studies}

\section{B.1. Urea production plant}

The dimensions of equipment items in the Urea plant are given in Table B.1. Table B.2 shows the connection cost, connection heights, horizontal and vertical pumping costs, as well as other required data.

Table B.1: Equipment dimensions for the Urea production plant

\begin{tabular}{clccc}
$\begin{array}{c}\text { Equipment } \\
\text { item }\end{array}$ & Description & $\alpha_{i}(\mathrm{~m})$ & $\beta_{i}(\mathrm{~m})$ & $\gamma_{i}(\mathrm{~m})$ \\
\hline 1 & Flash drum & 1.9812 & 1.9812 & 6.0960 \\
2 & Reactor 1 & 2.4384 & 2.4384 & 28.956 \\
3 & Reactor 2 & 1.5240 & 1.5240 & 5.7912 \\
4 & Distillation Column 1 & 1.0668 & 1.0668 & 14.6304 \\
5 & Distillation Column 2 & 0.6096 & 0.6096 & 7.3152 \\
6 & Reactor 3 & 0.7620 & 0.7620 & 3.3528 \\
7 & Reactor 4 & 1.2192 & 1.2192 & 5.0292 \\
8 & Separator & 1.0668 & 1.0668 & 3.6576 \\
\hline
\end{tabular}

Table B.2: Parameters for the Urea production plant

(a) Connection and pumping costs, and connection heights

\begin{tabular}{cccccc} 
Connection & $C_{i j}^{c}(\mathrm{rmu} / \mathrm{m})$ & $C_{i j}^{h}(\mathrm{rmu} / \mathrm{m})$ & $C_{i j}^{v}(\mathrm{rmu} / \mathrm{m})$ & $O P_{i j}(\mathrm{~m})$ & $I P_{i j}(\mathrm{~m})$ \\
\hline 1.4 & 38.0 & 662.2 & 6621.8 & 0.0000 & 12.8016 \\
4.3 & 161.0 & 513.3 & 5133.4 & 14.6304 & 4.6330 \\
4.7 & 25.0 & 332.2 & 3321.8 & 0.0000 & 1.0058 \\
7.8 & 25.0 & 332.2 & 3321.8 & 1.0058 & 2.9261 \\
3.2 & 124.0 & 803.5 & 8035.1 & 1.1582 & 0.0000 \\
2.1 & 103.0 & 803.5 & 8035.1 & 28.9560 & 4.5720 \\
1.5 & 62.0 & 141.3 & 1413.3 & 6.0960 & 1.8288 \\
8.6 & 14.0 & 59.0 & 590.0 & 3.6576 & 3.3528 \\
6.5 & 13.0 & 59.0 & 590.0 & 3.3528 & 5.4864 \\
5.3 & 17.0 & 156.2 & 1561.7 & 0.0000 & 4.6330 \\
\hline
\end{tabular}

(b) Other Parameters

\begin{tabular}{lr} 
Parameters & Value \\
\hline$|K|$ & 4 \\
$F C 1(\mathrm{rmu})$ & 3,200 \\
$F C 2\left(\mathrm{rmu} / \mathrm{m}^{2}\right)$ & 120 \\
$L C\left(\mathrm{rmu} / \mathrm{m}^{2}\right)$ & 420 \\
$F H(\mathrm{~m})$ & 8.0 \\
\hline
\end{tabular}


B.2. Crude distillation plant with pre-heating train (CDU) plant)

The dimensions of equipment items in the CDU plant are given in Table B.3. Table B.4 shows the connection cost, connection heights, horizontal and vertical pumping costs, as well as other required data.

Table B.3: Equipment dimensions for the CDU plant

\begin{tabular}{clccc}
$\begin{array}{c}\text { Equipment } \\
\text { item }\end{array}$ & Description & $\alpha_{i}(\mathrm{~m})$ & $\beta_{i}(\mathrm{~m})$ & $\gamma_{i}(\mathrm{~m})$ \\
\hline 1 & Crude preheater 1 & 6.000 & 0.974 & 0.974 \\
2 & Crude preheater 2 & 2.550 & 0.620 & 0.620 \\
3 & Desalter & 5.572 & 3.715 & 3.715 \\
4 & Preflash heater & 2.550 & 0.774 & 0.774 \\
5 & Preflash drum & 5.251 & 5.251 & 7.877 \\
6 & Fired heater (CDU) & 3.922 & 3.922 & 17.600 \\
7 & Crude distillation tower & 12.300 & 12.300 & 14.500 \\
8 & Naphtha condenser & 1.789 & 1.193 & 1.193 \\
9 & Kerosene SS & 1.500 & 1.500 & 3.900 \\
10 & Diesel SS & 1.500 & 1.500 & 3.900 \\
11 & AGO SS & 1.500 & 1.500 & 3.900 \\
12 & Fired heater (VDU) & 3.922 & 3.922 & 17.600 \\
13 & Vacuum distillation tower & 9.410 & 9.410 & 4.500 \\
14 & Kerosene reboiler & 3.050 & 2.033 & 2.033 \\
15 & Debutaniser & 5.337 & 5.337 & 24.750 \\
16 & Stabilised Naphtha condenser & 1.789 & 1.193 & 1.193 \\
17 & Debutaniser reboiler & 1.789 & 1.193 & 1.193 \\
\hline
\end{tabular}


Table B.4: Parameters for the CDU plant

(a) Connection and pumping costs, and connection heights

\begin{tabular}{cccccc} 
Connection & $C_{i j}^{c}(\mathrm{rmu} / \mathrm{m})$ & $C_{i j}^{h}(\mathrm{rmu} / \mathrm{m})$ & $C_{i j}^{v}(\mathrm{rmu} / \mathrm{m})$ & $O P_{i j}(\mathrm{~m})$ & $I P_{i j}(\mathrm{~m})$ \\
\hline 1.2 & 550.3 & $2,481.0$ & $24,810.0$ & 0.000 & 0.620 \\
2.3 & 550.3 & $2,481.0$ & $24,810.0$ & 0.000 & 3.715 \\
3.4 & 550.3 & $2,481.0$ & $24,810.0$ & 1.857 & 0.774 \\
4.5 & 531.4 & $2,395.6$ & $23,955.8$ & 0.000 & 3.938 \\
5.6 & 519.2 & $2,340.5$ & $23,405.0$ & 0.000 & 0.000 \\
6.7 & 519.2 & $2,340.5$ & $23,405.0$ & 4.280 & 0.750 \\
7.1 & 245.3 & $1,106.0$ & $11,059.9$ & 10.000 & 0.974 \\
7.2 & 155.0 & 698.9 & $6,988.8$ & 6.250 & 0.620 \\
7.4 & 161.6 & 728.4 & $7,284.1$ & 3.750 & 0.774 \\
1.7 & 245.3 & $1,106.0$ & $11,059.9$ & 0.000 & 10.750 \\
2.7 & 155.0 & 698.9 & $6,988.8$ & 0.000 & 6.750 \\
4.7 & 161.6 & 728.4 & $7,284.1$ & 0.000 & 4.250 \\
7.8 & 206.1 & 929.2 & $9,291.8$ & 14.500 & 0.597 \\
8.7 & 102.1 & 460.2 & $4,602.0$ & 0.000 & 14.250 \\
7.9 & 57.4 & 258.6 & $2,586.4$ & 10.250 & 3.650 \\
9.7 & 11.0 & 49.7 & 496.9 & 3.900 & 10.750 \\
9.14 & 67.9 & 306.2 & $3,061.9$ & 0.000 & 0.000 \\
14.9 & 21.6 & 97.2 & 972.4 & 2.033 & 2.650 \\
7.10 & 117.5 & 529.8 & $5,297.9$ & 6.250 & 3.650 \\
10.7 & 17.4 & 78.5 & 785.2 & 3.900 & 6.750 \\
7.11 & 31.4 & 141.7 & $1,416.6$ & 3.750 & 3.650 \\
11.7 & 8.0 & 36.0 & 359.6 & 3.900 & 4.250 \\
7.12 & 248.3 & $1,119.2$ & $11,191.6$ & 0.000 & 0.000 \\
12.13 & 248.3 & $1,119.2$ & $11,191.6$ & 4.280 & 0.250 \\
8.15 & 99.0 & 446.2 & $4,462.2$ & 0.000 & 12.925 \\
15.16 & 50.6 & 228.3 & $2,282.8$ & 24.750 & 0.597 \\
15.17 & 212.7 & 958.7 & $9,587.5$ & 0.000 & 0.000 \\
16.15 & 30.4 & 137.0 & $1,369.7$ & 0.000 & 24.475 \\
17.15 & 133.9 & 603.8 & $6,038.4$ & 1.193 & 0.275 \\
\hline & & & & & \\
& & & & &
\end{tabular}

(b) Other Parameters

\begin{tabular}{lr} 
Parameters & Value \\
\hline$|K|$ & 7 \\
$F C 1(\mathrm{rmu})$ & 3,330 \\
$F C 2\left(\mathrm{rmu} / \mathrm{m}^{2}\right)$ & 33.3 \\
$L C\left(\mathrm{rmu} / \mathrm{m}^{2}\right)$ & 666 \\
$F H(\mathrm{~m})$ & 5.0 \\
\hline
\end{tabular}




\section{B.3. Liquefied natural gas (LNG) plant}

Table B.5 shows the dimensions of equipment items and Table B.6 shows the connection cost, connection heights, horizontal and vertical pumping costs, as well as other required data for the LNG plant.

Table B.5: Equipment dimensions for the LNG plant

\begin{tabular}{clccc}
$\begin{array}{c}\text { Equipment } \\
\text { item }\end{array}$ & Description & $\alpha_{i}(\mathrm{~m})$ & $\beta_{i}(\mathrm{~m})$ & $\gamma_{i}(\mathrm{~m})$ \\
\hline 1 & PMR compressor LP suction drum & 3.613 & 3.613 & 4.603 \\
2 & PMR compressor HP suction drum & 3.217 & 3.217 & 4.900 \\
3 & PMR compressor & 18.809 & 5.939 & 5.741 \\
4 & PMR compressor cooler & 2.969 & 1.979 & 2.969 \\
5 & Overhead crane for PMR compressor & 22.769 & 15.839 & 5.939 \\
6 & SW cooler 1 & 7.919 & 1.979 & 4.949 \\
7 & SW cooler 2 & 7.919 & 1.979 & 4.949 \\
8 & PMR receiver & 4.157 & 4.157 & 9.800 \\
9 & LP precool exchanger & 4.157 & 4.157 & 21.086 \\
10 & HP precool exchanger & 4.355 & 4.355 & 21.779 \\
11 & Joule-Thomson valve 1 & 0.989 & 0.989 & 0.989 \\
12 & Joule-Thomson valve 2 & 0.989 & 0.989 & 0.989 \\
13 & MR separator 1 & 4.454 & 4.454 & 12.869 \\
14 & MCHE & 5.642 & 5.642 & 41.579 \\
15 & MR compressor suction drum & 5.444 & 5.444 & 8.909 \\
16 & MR compressor & 17.126 & 5.939 & 5.939 \\
17 & MR compressor cooler & 2.969 & 1.979 & 2.969 \\
18 & Overhead crane for MR Compressor & 22.769 & 15.839 & 5.939 \\
19 & SW cooler 3 & 3.959 & 2.474 & 2.969 \\
20 & SW cooler 4 & 3.959 & 2.474 & 2.969 \\
21 & Joule-Thomson valve 3 & 1.484 & 1.484 & 1.484 \\
22 & Joule-Thomson valve 4 & 1.484 & 1.484 & 1.484 \\
\hline
\end{tabular}


Table B.6: Parameters for the LNG plant

(a) Connection and pumping costs, and connection heights

\begin{tabular}{cccccc} 
Connection & $C_{i j}^{c}(\mathrm{rmu} / \mathrm{m})$ & $C_{i j}^{h}(\mathrm{rmu} / \mathrm{m})$ & $C_{i j}^{v}(\mathrm{rmu} / \mathrm{m})$ & $O P_{i j}(\mathrm{~m})$ & $I P_{i j}(\mathrm{~m})$ \\
\hline 2.3 & 150 & 750 & 7500 & 2.4500 & 2.8705 \\
3.6 & 150 & 750 & 7500 & 2.8705 & 2.4745 \\
3.7 & 150 & 750 & 7500 & 2.8705 & 2.4745 \\
7.2 & 150 & 750 & 7500 & 2.4745 & 2.4500 \\
8.10 & 150 & 750 & 7500 & 8.9000 & 4.0000 \\
10.11 & 150 & 750 & 7500 & 18.8895 & 0.4945 \\
11.10 & 150 & 750 & 7500 & 0.4945 & 18.8895 \\
9.10 & 150 & 750 & 7500 & 4.0000 & 18.8895 \\
10.9 & 150 & 750 & 7500 & 18.8598 & 4.0000 \\
12.9 & 70 & 250 & 2500 & 0.4945 & 18.5430 \\
9.12 & 70 & 250 & 2500 & 18.4530 & 0.4945 \\
13.14 & 150 & 750 & 7500 & 4.0000 & 12.0000 \\
14.15 & 150 & 750 & 7500 & 4.0000 & 4.0000 \\
15.16 & 150 & 750 & 7500 & 8.4545 & 2.9695 \\
16.17 & 150 & 750 & 7500 & 2.9795 & 1.4845 \\
17.16 & 150 & 750 & 7500 & 1.4845 & 2.9695 \\
14.21 & 70 & 250 & 2500 & 28.0000 & 0.7420 \\
21.14 & 70 & 250 & 2500 & 0.7420 & 28.0000 \\
16.19 & 150 & 750 & 7500 & 2.9695 & 1.4845 \\
19.16 & 150 & 750 & 7500 & 1.4845 & 2.9695 \\
16.20 & 150 & 750 & 7500 & 2.9695 & 1.4845 \\
20.16 & 150 & 750 & 7500 & 1.4845 & 2.9695 \\
22.14 & 150 & 750 & 7500 & 0.7420 & 36.7895 \\
14.22 & 150 & 750 & 7500 & 36.7895 & 0.7420 \\
10.2 & 150 & 750 & 7500 & 12.0000 & 2.4500 \\
9.1 & 150 & 750 & 7500 & 12.0000 & 2.3015 \\
6.8 & 150 & 750 & 7500 & 2.4745 & 8.9000 \\
14.9 & 150 & 750 & 7500 & 20.0000 & 12.0000 \\
10.13 & 150 & 750 & 7500 & 4.0000 & 4.0000 \\
\hline & & & & &
\end{tabular}

(b) Other Parameters

\begin{tabular}{lr} 
Parameters & Value \\
\hline$|K|$ & 5 \\
$F C 1(\mathrm{rmu})$ & 4,600 \\
$F C 2\left(\mathrm{rmu} / \mathrm{m}^{2}\right)$ & 33.3 \\
$L C\left(\mathrm{rmu} / \mathrm{m}^{2}\right)$ & 666 \\
$F H(\mathrm{~m})$ & 8.0 \\
\hline
\end{tabular}


B.4. Crude oil \& gas processing (COGP) plant

Table B.7 shows the dimensions of equipment items and Table B. 8 shows the connection cost, connection heights, horizontal and vertical pumping costs, as well as other required data for the COGP plant.

Table B.7: Equipment dimensions for the COGP plant

\begin{tabular}{clccc}
$\begin{array}{c}\text { Equipment } \\
\text { item }\end{array}$ & Description & $\alpha_{i}(\mathrm{~m})$ & $\beta_{i}(\mathrm{~m})$ & $\gamma_{i}(\mathrm{~m})$ \\
\hline 1 & Separator & 20.000 & 5.000 & 5.000 \\
2 & KO drum & 16.000 & 4.000 & 4.000 \\
3 & Contactor 1 & 3.000 & 3.000 & 8.000 \\
4 & Contactor 2 & 2.000 & 2.000 & 5.333 \\
5 & Compressor 1 & 8.000 & 3.000 & 3.000 \\
6 & Compressor 2 & 5.333 & 2.000 & 2.000 \\
7 & Mixer 1 & 1.000 & 1.000 & 1.000 \\
8 & Heat exchanger 1 & 8.000 & 2.500 & 2.500 \\
9 & Heat exchanger 2 & 9.600 & 3.600 & 3.600 \\
10 & Heat exchanger 3 & 14.400 & 4.500 & 4.500 \\
11 & Contactor 3 & 3.000 & 3.000 & 9.000 \\
12 & Contactor 4 & 3.600 & 3.600 & 10.800 \\
13 & Contactor 5 & 5.400 & 5.400 & 16.200 \\
14 & Compressor 3 & 6.400 & 2.400 & 2.400 \\
15 & Compressor 4 & 7.680 & 2.880 & 2.880 \\
16 & Compressor 5 & 11.520 & 4.320 & 4.320 \\
17 & Heat exchanger 4 & 6.000 & 1.875 & 1.875 \\
18 & Heat exchanger 5 & 7.200 & 2.700 & 2.700 \\
19 & Heat exchanger 6 & 10.800 & 3.375 & 3.375 \\
20 & Contactor 6 & 2.400 & 2.400 & 7.200 \\
21 & Contactor 7 & 2.880 & 2.880 & 8.640 \\
22 & Contactor 8 & 4.320 & 4.320 & 12.960 \\
23 & Compressor 6 & 5.760 & 2.160 & 2.160 \\
24 & Compressor 7 & 6.912 & 2.592 & 2.592 \\
25 & Compressor 8 & 10.368 & 3.888 & 3.888 \\
\hline & & & &
\end{tabular}


Table B.8: Parameters for the COGP plant

(a) Connection and pumping costs, and connection heights

\begin{tabular}{cccccc} 
Connection & $C_{i j}^{c}(\mathrm{rmu} / \mathrm{m})$ & $C_{i j}^{h}(\mathrm{rmu} / \mathrm{m})$ & $C_{i j}^{v}(\mathrm{rmu} / \mathrm{m})$ & $O P_{i j}(\mathrm{~m})$ & $I P_{i j}(\mathrm{~m})$ \\
\hline 1.7 & 50.00 & 225.00 & 2250.0 & 0.000 & 1.000 \\
1.2 & 200.00 & 900.00 & 9000.0 & 0.000 & 2.000 \\
2.4 & 72.00 & 324.00 & 3240.0 & 0.000 & 2.667 \\
4.6 & 72.00 & 324.00 & 3240.0 & 5.333 & 2.000 \\
6.7 & 72.00 & 324.00 & 3240.0 & 2.000 & 1.000 \\
5.7 & 108.00 & 486.00 & 4860.0 & 3.000 & 1.000 \\
2.3 & 108.00 & 486.00 & 4860.0 & 0.000 & 4.000 \\
3.5 & 108.00 & 486.00 & 4860.0 & 8.000 & 3.000 \\
7.8 & 57.50 & 258.75 & 2587.5 & 0.000 & 2.500 \\
7.9 & 69.00 & 310.50 & 3105.0 & 0.000 & 3.600 \\
7.10 & 103.50 & 465.75 & 4657.5 & 0.000 & 4.500 \\
8.11 & 57.50 & 258.75 & 2587.5 & 0.000 & 4.500 \\
11.14 & 46.00 & 207.00 & 2070.0 & 9.000 & 2.400 \\
14.17 & 46.00 & 207.00 & 2070.0 & 2.400 & 1.875 \\
17.20 & 46.00 & 207.00 & 2070.0 & 0.000 & 3.600 \\
20.23 & 41.40 & 186.30 & 1863.0 & 7.200 & 2.160 \\
9.12 & 69.00 & 310.50 & 3105.0 & 0.000 & 5.400 \\
12.15 & 55.20 & 248.40 & 2484.0 & 10.800 & 2.880 \\
15.18 & 55.20 & 248.40 & 2484.0 & 2.880 & 2.700 \\
18.21 & 55.20 & 248.40 & 2484.0 & 0.000 & 4.320 \\
21.24 & 49.68 & 223.56 & 2235.6 & 8.640 & 2.592 \\
10.13 & 103.50 & 465.75 & 4657.5 & 0.000 & 8.100 \\
13.16 & 82.80 & 372.60 & 3726.0 & 16.200 & 4.320 \\
16.19 & 82.80 & 372.60 & 3726.0 & 4.320 & 3.375 \\
19.22 & 82.80 & 372.60 & 3726.0 & 0.000 & 6.480 \\
22.25 & 74.52 & 335.34 & 3353.4 & 12.960 & 3.888 \\
\hline & & & & &
\end{tabular}

(b) Other Parameters

\begin{tabular}{lr} 
Parameters & Value \\
\hline$|K|$ & 7 \\
$F C 1(\mathrm{rmu})$ & 3,330 \\
$F C 2\left(\mathrm{rmu} / \mathrm{m}^{2}\right)$ & 33.3 \\
$L C\left(\mathrm{rmu} / \mathrm{m}^{2}\right)$ & 666 \\
$F H(\mathrm{~m})$ & 5.0 \\
\hline
\end{tabular}




\section{References}

American Institute of Chemical Engineers, 1994. Dow's fire \& explosion index hazard classification guide. Vol. 7. John Wiley \& Sons, Inc., Hoboken, NJ, USA.

Barbosa-Póvoa, A. P., Mateus, R., Novais, A. Q., 2002. Optimal 3D layout of industrial facilities. Int. J. Prod. Res. 40, 1669-1698.

Brunoro Ahumada, C., Quddus, N., Mannan, M. S., 2018. A method for facility layout optimisation including stochastic risk assessment. Process Saf. Environ. Prot. 117, 616-628.

de Lira-Flores, J., Vázquez-Román, R., López-Molina, A., Mannan, M. S., 2014. A MINLP approach for layout designs based on the domino hazard index. J. Loss Prev. Process Ind. 30, 219-227.

Ejeh, J. O., Liu, S., Chalchooghi, M. M., Papageorgiou, L. G., 2018a. Optimization-based approach for process plant layout. Ind. Eng. Chem. Res. 57, 10482-10490.

Ejeh, J. O., Liu, S., Papageorgiou, L. G., 2018b. Optimal multi-floor process plant layout with production sections. Chem. Eng. Res. Des. 137, 488-501.

Furuholmen, M., Glette, K., Hovin, M., Torresen, J., 2010. A coevolutionary, hyper heuristic approach to the optimization of three-dimensional process plant layouts - A comparative study. In: IEEE Congress on Evolutionary Computation. IEEE, pp. 1-8.

GAMS Development Corporation, 2018. General algebraic modeling system (GAMS) release 25.0.2.

Georgiadis, M., Macchietto, S., 1997. Layout of process plants: A novel approach. Comput. Chem. Eng. 21, S337-S342.

Guirardello, R., Swaney, R. E., 2005. Optimization of process plant layout with pipe routing. Comput. Chem. Eng. 30, 99-114.

Hosseini-Nasab, H., Fereidouni, S., Fatemi Ghomi, S. M. T., Fakhrzad, M. B., 2018. Classification of facility layout problems: a review study. Int. J. Adv. Manuf. Technol. 94, 957-977.

Hwang, J., Lee, K. Y., 2014. Optimal liquefaction process cycle considering simplicity and efficiency for LNG FPSO at FEED stage. Computers and Chemical Engineering 63, 1-33.

Kheirkhah, A., Navidi, H., Messi Bidgoli, M., 2015. Dynamic facility layout problem: a new bilevel formulation and some metaheuristic solution methods. IEEE Trans. Eng. Manag. 62, 396-410. 
Kondili, E., Pantelides, C. C., Sargent, R. W. H., 1993. A general algorithm for short-term scheduling of batch operations-I. MILP formulation. Comput. Chem. Eng. 17, 211-227.

López-Molina, A., Vázquez-Román, R., Mannan, M. S., Félix-Flores, M. G., 2013. An approach for domino effect reduction based on optimal layouts. J. Loss Prev. Process Ind. 26, 887-894.

Moran, S., 2017. Process plant layout, 2nd Edition. Butterworth-Heinemann.

Nabavi, S., Taghipour, A., Mohammadpour Gorji, A., 2016. Optimization of facility layout of tank farms using genetic algorithm and fireball scenario. Chem. Prod. Process Model. 11, 149-157.

Papageorgiou, L. G., Rotstein, G. E., 1998. Continuous-domain mathematical models for optimal process plant layout. Ind. Eng. Chem. Res. 37, 3631-3639.

Park, P. J., Lee, C. J., 2015. The research of optimal plant layout optimization based on particle swarm optimization for ethylene oxide plant. J. Korean Soc. Saf. 30, 32-37.

Patsiatzis, D. I., Knight, G., Papageorgiou, L. G., 2004. An MILP approach to safe process plant layout. Chem. Eng. Res. Des. 82, 579-586.

Patsiatzis, D. I., Papageorgiou, L. G., 2002. Optimal multi-floor process plant layout. Comput. Chem. Eng. 26, 575-583.

Patsiatzis, D. I., Papageorgiou, L. G., 2003. Efficient solution approaches for the multifloor process plant layout problem. Ind. Eng. Chem. Res. 42, 811-824.

Patsiatzis, D. I., Xu, G., Papageorgiou, L. G., 2005. Layout aspects of pipeless batch plants. Ind. Eng. Chem. Res. 44, 5672-5679.

Penteado, F. D., Ciric, A. R., 1996. An MINLP approach for safe process plant layout. Ind. Eng. Chem. Res. 35, 1354-1361.

Tugnoli, A., Khan, F., Amyotte, P., Cozzani, V., 2008. Safety assessment in plant layout design using indexing approach: Implementing inherent safety perspective. Part 2-Domino Hazard Index and case study. J. Hazard. Mater. $160,110-121$.

Xu, G., Papageorgiou, L. G., 2007. A construction-based approach to process plant layout using mixed-integer optimization. Ind. Eng. Chem. Res. 46, 351358.

Xu, G., Papageorgiou, L. G., 2009. Process plant layout using an improvementtype algorithm. Chem. Eng. Res. Des. 87, 780-788. 